\title{
Para além da interpretação do papel da agricultura no desenvolvimento econômico brasileiro: uma leitura sob perspectiva evolucionária-institucionalista
}

\author{
Pedro Xavier da Silva ${ }^{1}$ \\ Sílvio Antonio Ferraz Cario ${ }^{2}$
}

\section{RESUMO}

Abordagens teórico-analíticas evolucionário-institucionalistas se propõem a investigar processos de desenvolvimento por meio do compartilhamento dos arcabouços teóricos da Economia Institucionalista e da Economia Evolucionária. Nesse sentido, o presente texto buscou aplicar tal procedimento metodológico à discussão sobre o cenário atual do desenvolvimento rural brasileiro. Por meio de Análise de Conteúdo se possibilitou extrair argumentos de dois artigos de relevância nacional sobre o tema. A principal questão observada se refere à segregação de um grande grupo de pequenos produtores agrícolas que se construiu à margem dos avanços tecnológicos galgados pelo competitivo padrão produtivo do Agronegócio nacional. As abordagens analisadas, embora de relevante descrição, não colocam em evidencia desenhos institucionais que envolvem o contexto rural. Lançando mão de categorias analíticas postas por Veblen, North, Hodgson, Nelson, entre outros, se fez possível realizar inferências sólidas em relação ao processo de incompatibilidade de absorção deste padrão tecnológico, por um lado, e da constante concentração de produção e renda agrícola, por outro.

Palavras-chave: Instituições; Desenvolvimento Rural; Hábitos

\begin{abstract}
We suggest that Evolutionary-Institutionalist Theoretical and Analytical Approaches are proposed to investigate development processes through the sharing of theoretical frameworks from Institutionalism Economics and Evolutionary Economics. In this sense, this text show the utilization of this kind of methodological approach to discuss the current scenario of the Brazilian rural development. Through Content Analysis we extract arguments from two relevant papers on the topic. The main issue observed refers to the segregation of a large group of less competitive smallhold farmers who stay on the margins of technological advances, compared with the National Agribusiness standard. The texts analyzed, although bouth present relevant description, do not put in evidence institutional designs that involve the rural context. Drawing on analytical categories placed by Veblen, North Hodgson, Nelson, among others, it was possible to perform solid inferences regarding absorption incompatibility process of this standard technologies for the smallholders and constant concentration of production and farm income for industrial production.
\end{abstract}

Keywords: Institutions; Rural Developments; Habits; Technology

\footnotetext{
${ }^{1}$ Médico Veterinário; Mestre em Agronegócios pelo PPG-Agronegócios - Universidade Federal do Rio Grande do Sul; Doutorando pelo PPG-Administração Centro Sócio-Econômico - Universidade Federal de Santa Catarina; xavierdasilvapedro@gmail.com

$\frac{{ }^{2}}{2}$ Professor do Departamento de Economia; Núcleo de Economia Industrial e da Tecnologia; Centro SócioEconômico - Universidade Federal de Santa Catarina; fecario@yahoo.com.br
} 


\section{INTRODUÇÃO}

O percurso histórico particular de desenvolvimento de cada nação cria um cenário econômico e político sustentado por uma estrutura institucional substantiva que rege os diferentes mercados (de trabalho, de terra, de capital e de bens), e as instituições, grupos e regras - normas ou padrões de comportamento, formas institucionais, padrões de organização das firmas, ou, ainda, como direito de propriedade (CONCEIÇÃO, 2001) que determinam o contexto para as atividades econômicas. Elas assumiram seu caráter moderno como soluções para uma ampla gama de problemas sociais e políticos.

Em consonância, Zysman (1994) indica que tal estrutura institucional da economia, combinada com a sua estrutura industrial no sentido clássico da organização industrial, modela um sistema de incentivos e contrangimentos (empecilhos) que define os interesses, molda e canaliza as ações dos atores. Este sistema de interesses e interações entre os agentes promove uma lógica política particular a cada mercado que, por sua vez, promove diferentes lógicas de mercados. Tecnologia e as características do ambiente institucional e das firmas - em conjunto - proporcionam padrões singulares de desenvolvimento econômico, demandando para suas investigações análises interdisciplinares e históricas (CONCEIÇÃO, 2008). Instituições, portanto, sejam elas formais ou informais, são valores, aspectos culturais, regras, normas, leis, códigos de conduta, que influenciam diretamente a forma como determinada sociedade se constitui, lida com seus problemas e toma suas decisões econômicas. Evidente, portanto, é o caráter de intimidade entre o aparato institucional e os processos de desenvolvimento industrial e econômico.

Tendo sua origem nas obras e pesquisas de autores do final do século XIX e início do século XX, como os considerados fundadores do Antigo Institucionalismo, Thorstein Veblen, John Commons e Wesley Mitchel, que se propuseram a explicitar a significância das instituições na modulação dos processos que envolvem as relações sociais. No que se refere às implicações econômicas, o desenvolvimento institucionalista de Veblen, por exemplo, se fundamentou na crítica à ortodoxia neoclássica e no pressuposto de busca pelo equilíbrio, além da valorização dos processos de crescimento econômico e mudança tecnológica (CONCEIÇÃO, 2001). Dali as propostas econômicas institucionalistas tomaram rumos e linhas teóricas distintos que ora se aproximam, ora se distanciam dos fundamentos veblenianos. De qualquer forma, seu ferramental analítico se tornou fortuito no sentido de avaliar processos de desenvolvimento diversos, sendo eleito, aqui, para uma importante discussão contemporânea. 
Em 2006, o Instituto Brasileiro de Geografia e Estatística publicou o último levantamento censitário detalhado do ambiente rural do país. O Censo Agropecuário Brasileiro (IBGE, 2006) permitiu uma leitura minuciosa das situações agrícola e agrária do país, promovendo dados que, ao longo dos últimos anos, vêm sendo utilizados para inferências em investigações das mais distintas ordens. Uma delas foi publicada por Alves e Rocha (2010), e escancarou um cenário preocupante - principalmente referente às questões agrárias - em que a imensa maioria dos produtores rurais brasileiros estava alheia aos avanços tecnológicos e econômicos conquistados pelo setor agrícola do país. Expôs-se, portanto, uma situação conflitante para o desenvolvimento rural: ao passo que nos tornamos um competitivo agente em mercados agrícolas e desenvolvemos uma estrutura organizativa agroindustrial que alavancou significativamente nossos índices econômicos, apenas uma diminuta minoria de produtores se apropria da renda oriunda do campo.

Esta identificação incitou o debate acerca das suas consequiências, promovendo subsídios para textos e argumentações acadêmicas expressivas. Dois destes artigos comporão a principal fonte das informações aqui tratadas. O primeiro, publicado em 2013, intitula-se "As sete teses sobre o mundo rural brasileiro" (BUAINAIN et al, 2013) e ilustra a nova dinâmica da agricultura nacional, além do padrão tecnológico alcançado, permitindo posicionar o país de forma ímpar nos mercados globais. Este texto deixa evidente, porém, a preocupação dos autores em relação ao já mencionado aspecto concentrador do valor gerado. E é justamente este ponto que é discutido, em resposta às sete teses, no segundo texto em questão: “Considerações Acerca de Teses Recentes sobre o Mundo Rural Brasileiro” (MATTEI, 2014), que caracteriza uma crítica em relação à relativização das inúmeras faces do ambiente rural em prol da maximização da agricultura moderna. Embora os autores divirjam enquanto a relevância de questões como a importância de reforma agrária e o papel do Estado nos contextos agrário e agrícola, ambos relatam um fenômeno de industrialização da agricultura bastante presente na literatura sobre o tema. Com ampla contribuição de dados, em ambos os casos, traçam-se uma trajetória evolutiva da agropecuária nacional, sendo influenciada, sobremaneira, pelo ambiente institucional que também se mantém em constante evolução.

Com isso, buscou-se entender como se deu o processo de modernização da agricultura brasileira e seus efeitos sobre o desenvolvimento rural do país. Além disso, compreender os motivos pelos quais vem se constatando uma imensa discrepância entre dois diferentes grupos de agentes do campo, seja ele aquele diminuto em número de estabelecimentos e imenso em geração de riquezas - que está inserido aos mercados de forma competitiva e 
usufrui dos benefícios econômicos cujos quais são resultados da alta produtividade agrícola - seja aquele cujos produtores se posicionam à margem da tecnologia disponível para a produção.

Dado que a riqueza de dados do par de textos não apresente um ferramental teóricoanalítico que permita inferências que se distancie de pontos de vista fortemente ideológicos, é significativo apoiar uma comparação entre ambas as exposições em um arcabouço compatível. Sendo assim, nossas análises acerca deste cenário substantivo, se sustentará em categorias analíticas da Economia Institucionalista e Evolucionária.

Se propôs que, fundamentado nas reflexões retiradas dos textos, o supracitado fenômeno fosse avaliado perante conceitos enraizados no arcabouço teórico institucionalista e neoschumpeteriano. Para tal, o presente artigo é composto por, além da presente introdução e de uma seção demonstrativa dos procedimentos teóricos, uma seção que corresponde à demonstração do referencial teórico institucionalista, uma que corresponde à base para a discussão sobre o desenvolvimento rural brasileiro, a análise propriamente dita, considerações finais e referências bibliográficas.

\section{PROCEDIMENTOS METODOLÓGICOS}

A utilização dos textos referentes à evolução da agricultura e do ambiente rural brasileiro como um todo se propõe a apresentar trajetórias de desenvolvimento para as circunstâncias do rural brasileiro - entendendo este como um complexo das dimensões agrária e agrícola. Assim sendo, tais evidências foram analisadas com base nos conceitos teóricos da Economia Institucionalista e Evolucionária, sobretudo pelas categorias que apresentam raízes epistemológicas veblenianas. A análise de dados se baseou na proposta de Análise de Conteúdo de Bardin (2006), caracterizada por três fases distintas. Primeiramente foi realizada uma préanálise a partir de leitura flutuante sobre o material tomado como banco de dados, ou seja, os textos de que compõem a seção 4. A partir de uma reflexão acerca de suas proposições, iniciouse um processo de exploração do material com base na codificação e categorização das informações ali contidas.

Para a formulação das categorias, foram utilizados conceitos identificados como apropriados nas leituras referentes aos constructos evolucionário-institucionalistas, resultando em diferentes níveis de informação (Tema, Categoria e Indicador). Como "Tema", selecionaram-se nos textos passagens referentes às questões discutidas pelos autores, e que, de alguma forma, teriam vínculo com as propostas institucionalistas, tais como "políticas 
públicas", "tecnologia" e "desenvolvimento", por exemplo. A partir daí estes trechos, cujos temas se enquadrariam na proposta, foram categorizados por meio de uma transposição com base em categorias analíticas apresentadas na próxima seção (3).

\section{VEBLEN: EM BUSCA DE UMA ECONOMIA EVOLUCIONÁRIA}

Thorstein Veblen é tido como o pai do Institucionalismo por prospectar uma Economia Evolucionária que começa a ser apresentada no ano de 1898, quando publicou "Why Is Economics not an Evolutionary Science? (VEBLEN, 1998 [1898])”, postulando sua primeira crítica contundente ao estado da arte das Ciências Econômicas. No ano seguinte, ele publica “ $\boldsymbol{A}$ Teoria da Classe Ociosa” (VEBLEN, 1989 [1965]), que para Cavalieri (2015) e Monasterio (1999) seria a apresentação daquilo que se propunha a substituir a visão teleológica de se pensar Economia por uma proposta analítica Pós-Darwiniana ou Evolucionária.

De acordo com Cruz (2013), uma nítida lacuna entre o papel da terra como fonte de lucro especulativo em uma sociedade, no final do século XIX, que se direcionava à urbanoindustrialização tendo como agentes centrais homens de negócios por um lado e imigrantes por outro (que entendiam a terra como fonte de trabalho e meio de subsistência) influenciou diretamente seu entendimento do sistema no qual vivia. À época, constatava-se uma mudança importante entre as classes sociais americanas, em que, tanto agricultores do Oeste quanto a burguesia industrial se indispunham diante da ascensão de uma aristocracia beneficiada por acordos oligopolistas e aumento de poder político (CAVALIERI, 2015).

A idéia central darwinista estava no processo causal de evolução, ou seja, a influência do ambiente sobre o desenvolvimento das espécies e, este pressuposto, vinha sendo assimilado por diferentes ramos da ciência, à época. Com isso, teorias vinham sendo refutadas e modificadas. O grande trunfo de Thorstein foi trazer esta lógica evolucionista às ciências sociais. Ademais, como analogia bastante didática, o autor emprega termos como variância, herança e seleção natural para qualificar as mudanças comportamentais individuais e coletivas. Esta utilização correspondia à atmosfera acadêmica da Universidade de Chigado, onde uma notória propensão à assimilação e propagação da ciência pós-darwiniana se construía (RAYMER, 2013; CAVALIERI, 2015).

Esta proposta se concentrava na tese de que as demandas de uma sociedade formariam maneiras de interação dos homens com o mundo - interação esta que corresponderia à categoria analítica hábitos de vida (MONASTERIO, 1998). Tais hábitos de vida estariam vinculados, por um lado, com aspectos inerentes aos homens (os instintos) e, por outro, a hábitos de 
pensamento que estariam consolidados no senso coletivo. Curioso é o processo dialético em que se consolidam estes hábitos de pensamento, ou seja, por meio de maneiras de fazer (hábitos de vida) de outrora. Com isso, Veblen expunha que a Economia Pré-Evolucionária deveria se modificar, uma vez que esta se propusera à análise de uma dinâmica manufatureira que já não era hegemônica.

Neste contexto, a dinâmica social se daria partindo de instintos, expressões inatas e individuais (embora comuns), que se expandiriam até formar expressões coletivas e de impacto social significante, as instituições. Veblen, em The InstincThe Instinct of the Workmanship (1937 [1914]) explana sobre os instintos com maior veemência. Seriam eles: Instinto do Trabalho Eficaz (relacionado à busca por eficiência), Instinto Predatório (cujo propósito final seria a extração), Instinto Parental (relacionado aos cuidados coletivos) e o Instinto da Curiosidade Vã (cujo vínculo principal dado pelo autor se dá com a ciência). O Instinto Predatório, que teria seu surgimento a partir da passagem de uma fase pacífica selvagem para uma fase predatória, estaria relacionado com a competição e se tornaria amplificado em uma sociedade industrial (VEBLEN, 1965).

Hábitos de vida ou instituições estão intimamente relacionados aos hábitos de pensamento, e estes estariam enraizados no espírito humano (devido à relevância dos instintos). Veblen indica que, devido à fuga de situações de mudança, as pessoas tendem a manter seus hábitos indefinidamente, exceto em circunstâncias necessárias. E estas mudanças institucionais, portanto, se dariam por forma coercitiva devido à situação que se impôs (VEBLEN, 1965). Além disso, este processo coercitivo e de "seleção competitiva" das instituições é vagaroso, indicando que quando há sua ocorrência, a situação é outra e as demandas são outras. O mesmo ocorreria com as leis (VEBLEN, 1937), visto que configuram instituições forjadas em hábitos passados.

Outra colocação importante é que as emulações dos hábitos de vida e de pensamento se dão por consensos, ou seja, dependem da aceitação de um grupo dominante. Sendo assim, instituições são eleitas conforme interesses de tais grupos (VEBLEN, 1965), podendo representar a manutenção de situações indesejadas para determinado grupo social. $\mathrm{O}$ mesmo ocorreria com a construção do conhecimento e a produção e inserção de tecnologias. Aquilo que Veblen chama de "Classe Ociosa" (grupo dominante que, por possuir o capital, se abstém das funções produtivas) poderia, por vezes, retardar o progresso e em virtude da manutenção de sua situação. Este ponto, de certa forma, se distancia da proposição darwiniana de que seleção resultaria em evolução. Embora estes pressupostos seminais tenham-se postos em espera (ou 
melhorar, tenham sido postos em espera) posteriormente à Segunda Guerra Mundial, o Institucionalismo tornou-se relevante, novamente no quarto quartil do século passado.

Análises políco-econômicas hodiernas se "encaixam" de forma significativa em uma ou mais das correntes institucionalistas disseminadas, quais sejam o Antigo Institucionalismo, a Nova Economia Institucional e o Neo-Institucionalismo. Veblen, ao propor uma Economia Pós-Darwiniana, se fundamentou na crítica à busca pelo equilíbrio perfeito da ortodoxia (neo)clássica e no foco na dinâmica das instituições socioculturais diante do crescimento econômico e da mudança tecnológica (CONCEIÇÃO, 2001).

Para a Nova Economia Institucional - ramo institucionalista cujos principais expoentes se tornaram Douglas North e Oliver Williamson - o objetivo fundamental seria estudar o custo das transações como determinante das formas de coordenação da produção, ou seja, a estrutura de governança de uma determinada cadeia produtiva, envolvida em um arcabouço analítico institucional.

Para isso, utilizam-se como unidades analíticas as próprias transações. Nessa proposta as instituições recebem ênfase, podendo ser instituições informais (como costumes, tradições, códigos de conduta e tabus) ou formais, que são, por exemplo, as leis e os direitos de propriedade (FARINA, AZEVEDO E SAES, 1997), formando um ambiente institucional. O ambiente institucional, para North (1994) refere-se ao campo de atuação das organizações, limitando as ações dos agentes envolvidos no sistema em questão. Com isso, a forma como as instituições se arranjam e interagem com os indivíduos são determinantes para o desempenho econômico (NORTH, 1991;1990).

Esses arranjos formam um conjunto de normas que podem ser consideradas, como alguns autores o fazem, como as "Regras do Jogo", por condicionarem o aparecimento e seleção de formas de organização que compõem as diferentes estruturas de governança (CONCEIÇÃO, 2008). Essas "regras" definem o contexto dentro do qual as atividades econômicas ocorrem. As regras políticas, sociais e legais estabelecem a base para que se deem as relações referentes à produção, ao comércio e à distribuição. Independentemente chamam-se estruturas de governança (WILLIAMSON, 1985) ou mecanismos de enforcement (NORTH, 1990), a lógica argumentativa se dá no sentido da constituição de um conjunto de instrumentos que visam o cumprimento das regras e a restrição de padrões de comportamento. 
Os neo-institucionalistas, por sua vez, são enfáticos na proposição de uma (re)aproximação entre as abordagens modernas e o Antigo Institucionalismo à medida que consideram instituições não apenas restrições às ações dos agentes. Para este grupo, instituições correspondem, sobremaneira, a ferramentas de amplificação de pontos de vista eleitos pelo bom senso vigente. Estas seriam produto de um processo seletivo e coercitivo passado que decorre da forma como os homens enxergam as coisas (HODGSON, 1993). Para Conceição (2012), a abordagem institucional evolucionária proposta por Hodgson é emblemática por exaltar a obra de Veblen, aproximando evolucionismo e instituições. É o efeito da relação entre indivíduos e instituições que direcionam o crescimento econômico, sob influência de instintos.

Diante desta tríade relacional instintos-hábitos-instituições as decisões e ações individuais estariam fortemente vinculadas a idéia de rotina, repetições. Os hábitos não seriam, portanto, comportamentos, mas indicariam propensões de comportamento forjadas, de forma repetitiva, em um contexto histórico (HODGSON, 2002). Nelson ${ }^{3}$ (2008) se aproxima deste entendimento ao sugerir que instituições sejam definidas como a comunhão de fatores que moldam e sustentam tecnologias sociais em determinado contexto. Nesse sentido, tecnologias sociais corresponderiam àquelas instituições fundamentais, em uma população e contexto específicos, para a assimilação e propagação dos processos e formas de fazer as tarefas produtivas.

Com isso, embora algumas diferenças sejam demonstradas entre os distintos ramos da economia institucionalista, não se pretende, aqui, entrar a fundo em cada um dos arcabouços teóricos. Contudo, torna-se relevante a identificação de algumas categorias analíticas utilizadas e a concepção comum de que mercados são instituições específicas (ou sistemas de regras estabelecidas) e não as únicas e preponderantes expressões da interação humana (HODGSON, 2007).

\section{O STATUS QUO DO DESENVOLVIMENTO RURAL BRASILEIRO}

Conforme mencionado, esta discussão lançou mão dos pontos de vista de Buainain et al (2013) e Mattei (2014) acerca do desenvolvimento rural brasileiro. Comum entre os textos é a importância (e necessidade) dada ao fato que o desenvolvimento rural do país seja debatido de

3 Richard Nelson, embora corresponda a um expoente pesquisador do evolucionário da economia compartilha algumas concepções teóricas com os ramos institucionalistas. Para maior aprofundamento sugere-se a leitura de Hodgson (2007) e Conceição (2012). 
forma objetiva e com categorias analíticas comuns. Neles são demonstradas trajetórias de desenvolvimento, que, embora sejam interpretadas por meio de critérios distintos (na maior parte), fundamentam o cenário rural exposto como objeto de suas investigações.

Indiscutível, no entanto, é a menção feita - por ambos - acerca da histórica relevância do setor agrícola à formação econômica brasileira por meio de geração de divisas, o que reitera seu papel estratégico no contexto político-econômico. As principais convergências e divergências entre ambos os pontos de vista podem ser observadas na Tabela 1.

\subsection{As Sete Teses Sobre o Mundo Rural Brasileiro}

O texto "As Sete Teses Sobre o Mundo Rural Brasileiro" (BUAINAIN et al, 2013), tenta expor uma nova realidade notada nos ambientes de investigação agrícola e agrário no país em questão. Com assinatura de pesquisadores da Empresa Brasileira de Pesquisa Agropecuária (EMBRAPA), são apontadas as conseqüências estruturais e organizacionais da agricultura a partir (principalmente) de fenômenos político-econômicos nacionais e globais desencadeados a partir da década de 1990, tendo como objetivo geral discutir as mudanças do panorama rural brasileiro.

Buainain et al (2013) iniciam o referido artigo propondo que, atualmente, existem teses equivocadas e que não respeitam as mudanças do panorama do rural no país. Indicam que existe um hiato entre teoria e realidade que propaga afirmações equivocadas, que, de certa forma, tiveram relevância outrora, mas tornaram-se antiquadas diante dos avanços constatados nas análises hodiernas. Tais mudanças referem-se ao processo de industrialização da agropecuária brasileira que se destaca tanto como importante gerador de Produto Interno Bruto e empregos quanto, na visão dos pesquisadores, como vetor de desenvolvimento.

Tabela 1. Inferências sobre o desenvolvimento rural brasileiro a partir de Buainain et al (2013) e Mattei (2014):

\begin{tabular}{|l|l|l|}
\hline \multicolumn{1}{|c|}{ Pontos Convergentes } & \multicolumn{1}{|c|}{ MATTEI (2014) } & BUAINAIN et al (2013) \\
\hline \multicolumn{2}{|c|}{ opel da terra... } \\
$\begin{array}{l}\text { O estabelecimento de um novo } \\
\text { padrão de acumulação na } \\
\text { agricultura dá relevância a } \\
\begin{array}{l}\text { outros fatores produtivos, além } \\
\text { da terra. }\end{array}\end{array}$ & $\begin{array}{l}\text { Embora existam outros fatores } \\
\text { (principalmente referentes à inserção } \\
\text { tecnológica) determinantes para os } \\
\text { resultados agrícolas, a terra se mantém } \\
\text { como um importante ativo. }\end{array}$ & $\begin{array}{l}\text { A propriedade da terra perde } \\
\text { representatividade entre os fatores de } \\
\text { produção agrícola, o que afeta } \\
\text { diretamente o debate sobre a questão } \\
\text { agrária. }\end{array}$ \\
\hline
\end{tabular}




\begin{tabular}{|c|c|c|}
\hline Argumentação no texto $\rightarrow$ & $\begin{array}{l}\text { "Negar tal fato }<\text { a constante } \\
\text { valorização dos preços da terra, a } \\
\text { relevância da concentração da } \\
\text { propriedade da terra no processo de } \\
\text { expansão horizontal da agricultura > } \\
\text { supõe a artificialização da produção } \\
\text { agrícola, uma vez que esta continua } \\
\text { permanecendo assentada na terra, } \\
\text { independentemente dos insumos, } \\
\text { máquinas e equipamentos que são } \\
\text { utilizados." (p. 111-112) }\end{array}$ & $\begin{array}{l}\text { “(...) o novo padrão introduz o capital } \\
\text { “em todas as suas modalidades” no } \\
\text { centro do desenvolvimento agrícola e } \\
\text { agrário. Rebaixa o papel da terra, pois } \\
\text { a produção e as rendas agropecuárias } \\
\text { passam a depender, crescentemente, } \\
\text { dos investimentos em infra-estrutura, } \\
\text { máquinas, tecnologia e na qualidade da } \\
\text { própria terra, além de investimentos em } \\
\text { recursos ambientais e no treinamento } \\
\text { do capital humano.” (p.111) }\end{array}$ \\
\hline \multicolumn{3}{|c|}{ A questão agrária... } \\
\hline $\begin{array}{l}\text { O padrão tecnológico } \\
\text { hegemônico para a agricultura } \\
\text { nacional se propõe por questões } \\
\text { de produtividade e se assume } \\
\text { como garantia de } \\
\text { competitividade para o } \\
\text { agronegócio brasileiro. Contudo, } \\
\text { este mesmo padrão, segrega a } \\
\text { grande maioria dos produtores } \\
\text { rurais e concentra produção e } \\
\text { renda em poucas propriedades } \\
\text { rurais capacitadas às exigências } \\
\text { técnicas de operacionais } \\
\text { impostas. }\end{array}$ & $\begin{array}{l}\text { O argumento utilizado para subjugar a } \\
\text { necessidade de políticas de } \\
\text { redistribuição de terras é de viés } \\
\text { economicista e pertinente, somente, } \\
\text { no que se refere à produtividade } \\
\text { agrícola. O desenvolvimento rural } \\
\text { deveria ser analisado por distintas } \\
\text { dimensões. Assumir que a agricultura } \\
\text { focada exclusivamente em } \\
\text { produtividade seja o aquela "ideal" } \\
\text { deslegitima alternativas que possam } \\
\text { contribuir às questões ambientais e } \\
\text { sociais. }\end{array}$ & $\begin{array}{l}\text { Políticas de redistribuição de terras não } \\
\text { apresentam efeitos significativos no } \\
\text { ponto de vista de aumento de produção } \\
\text { e renda agrícola. Os produtores } \\
\text { marginalizados demandariam, portanto, } \\
\text { capacitação para absorção dos padrões } \\
\text { da agricultura moderna, não a inclusão } \\
\text { de novos produtores propensos ao } \\
\text { mesmo fenômeno. }\end{array}$ \\
\hline Argumentação no texto $\rightarrow$ & $\begin{array}{l}\text { “(...) }<\text { Em "As Sete Teses.. > a esfera } \\
\text { econômica é prevalece }(. . .)<\text { Em "As } \\
\text { Sete Teses.. > a esfera econômica é } \\
\text { prevalece e quem determina os rumos } \\
\text { do desenvolvimento agrário." (p.110) }\end{array}$ & $\begin{array}{c}\text { "Diferentemente do passado, a } \\
\text { incorporação de novas terras } \\
\text { explica pouco do crescimento da } \\
\text { produção, e o dinamismo da } \\
\text { agropecuária decorre } \\
\text { principalmente de investimentos e } \\
\text { da intensificação } \\
\text { tecnológica.(p.118)" }\end{array}$ \\
\hline \multicolumn{3}{|c|}{ O papel da Estado ... } \\
\hline $\begin{array}{l}\text { O processo de modernização da } \\
\text { agricultura se deu por meio de } \\
\text { políticas intervencionistas } \\
\text { pontuais; O aparato institucional } \\
\text { se modificou ao longo do tempo, } \\
\text { impactando nas formas de } \\
\text { organizativas das cadeias } \\
\text { agrícolas. }\end{array}$ & $\begin{array}{l}\text { Mesmo que na década de } 1990 \text { tenha- } \\
\text { se ocorrido uma redução em gastos } \\
\text { públicos totais com a produção rural, } \\
\text { políticas referentes à proteção de } \\
\text { propriedade intelectual, a aberturas } \\
\text { de linhas de crédito como o } \\
\text { PRONAF, a renuncias fiscais e } \\
\text { investimentos em empresas } \\
\text { agropecuárias nacionais com crédito } \\
\text { via BNDES interferem diretamente } \\
\text { nas contas públicas. Tais fatores, } \\
\text { para o autor, refutam a tese de "fuga } \\
\text { à francesa" do Estado. }\end{array}$ & $\begin{array}{l}\text { O Estado, desde a década de 1990, reduz } \\
\text { seus gastos diretos em financiamento da } \\
\text { agricultura. Mesmo assim, notou-se uma } \\
\text { vasta expansão produtiva desde esse } \\
\text { período. Os autores ligam tal inferência } \\
\text { a atuação de empresas privadas que à } \\
\text { medida que aumentam a capilaridade } \\
\text { tecnológica, atuam na realização de } \\
\text { investimentos na produção. Contudo, } \\
\text { aponta-se que ainda se mantém um } \\
\text { conservadorismo Estatal que modela o } \\
\text { ambiente institucional de forma } \\
\text { prejudicial aos avanços em } \\
\text { desenvolvimento rural. }\end{array}$ \\
\hline
\end{tabular}


Argumentação no texto $\rightarrow$
"Dentre essas contradições $<$ presentes em "As Sete Teses”> são destacadas a interpretação limitada sobre a relação entre o processo de modernização e o movimento demográfico ocorrido no país; a leitura e interpretação do papel do Estado a partir da década de 1990; a exemplificação da existência de um novo padrão de acumulação com base em afirmações que não têm qualquer aferição empírica; a negação do papel do Estado no apoio ao desenvolvimento rural; e a tradicional leitura equivocada da estrutura agrária do país. (p.114”)
"Durante o período inicial de modernização, esgotou-se um conjunto de "primeiras tarefas" de transformações rurais induzidas pelo Estado, combinando crédito rural, pesquisa agrícola e serviços de assistência técnica e extensão rural estatais. Nessa fase diversos agentes privados passaram a se dedicar à produção de pesquisa e a difundir inovações, além de disputar o bolo da riqueza. Paralelamente, o Estado foi "saindo à francesa", o que é comprovado pelos gastos públicos na agricultura. Abre-se assim uma nova fase, na qual os agentes privados serão

os principais atores do desenvolvimento. (p.120)"

Fonte: Elaborado pelos autores.

O texto de Buainain et al (2013) sustenta suas análises sobre três dimensões. Primeiramente a temporalidade do processo (quando), segundo, nos atores e grupos sociais (quem) e, por fim, nos catalisadores e oportunidades (como) que concretizaram as transformações referidas pelo conjunto das teses apresentadas. Sendo assim, brevemente, mencionam-se os efeitos do período entendido como "Revolução Verde" em que, inspirado no caso norte-americano e fundado em três grandes focos, capilarizaram-se ações de promoção de crédito rural subsidiado, extensão rural e pesquisa agrícola por instituições públicas. A partir daí, sugere-se que este ambiente institucional sedimentou a preparação para as mudanças que se deram na década de 1990, caracterizadas por "um novo padrão de financiamento da agricultura (que contou crescentemente com recursos privados), além de uma nova política cambial (em 1999), o que tornou os produtos de exportação mais competitivos” (BUAINAIN, 2013; p. 1165).

Ali, expõe-se a primeira tese, cujo foco está naquilo que é dito como uma nova dinâmica produtiva e econômico-social em que o padrão de acumulação da agricultura se dissolveu nas distintas esferas do capital, ao contrário do que ocorria antes, em que a terra era o bem principal. Sendo assim, a altíssima alocação de recursos em políticas de reforma agrária tornase obsoleta e tais recursos poderiam ser empregados com outros fins. Este posicionamento estratégico estaria vinculado à forma de desenvolvimento rural bifronte fotografada pelo texto, na qual um pequeníssimo grupo de produtores é responsável pela maior parte da renda bruta originária da produção agropecuária. Por um lado, concentra-se a produção, por outro 
seleciona-se o produtor e segrega um grupo enorme de indivíduos que não corresponde às exigências concorrenciais.

Essa suposição enfatiza a dissipação tecnológica no ambiente agrícola e exalta a forma como produção e renda do campo passam a depender dos investimentos crescentes em capital humano, recursos ambientais, infra-estrutura, maquinário, etc. Com isso, evidencia-se, também, o aumento da concorrência e a necessidade de aprimoramento das práticas produtivas. Ao mesmo tempo em que se demonstra a importância da tecnologia no campo, se indicam aspectos negativos para que esta seja dissipada e assimilada pelos agentes econômicos. Tais aspectos fazem menção à institucionalização da biotecnologia como foco de perigo ou dos danos da agricultura moderna ao meio ambiente e sua relação com o aquecimento global, por exemplo.

Os autores, à medida que trazem pontos de vista críticos às formas nas quais o status tecnológico prima pelo aumento de produtividade, desqualificam formas alternativas e seus pressupostos, uma vez que, para eles, "não correspondem ao cotidiano da agricultura" (BUAINAIN et al, 2013). Tal inviabilidade se concentra, com maior importância, na forte urbanização global demandante de produtos agroalimentares, na baixa disponibilidade e qualificação de mão de obra no campo, e na ineficiência de corresponder às demandas de segurança alimentar.

Outro ponto importante posto em caráter de tese é a menor participação dos gastos públicos no financiamento da agropecuária, indicando que um primeiro momento de intervenção para transformação do ambiente agropecuário teria passado e dado lugar a disseminação tecnológica por parte de empresas privadas, sendo estas os principais atores do desenvolvimento. Assim, Buainain et al (2013) indicam que o papel do Estado, hoje, seja outro, abrindo mão do financiamento direto e possibilitando que o ambiente institucional seja favorável aos altos padrões concorrenciais globais. A publicação deste texto tornou-se um material de subjetivo impacto no meio acadêmico, tanto pela contundência em suas análises e veemência em suas prospecções, quanto pela relevância dos autores em relação ao tema desenvolvimento rural. Com isso, críticas se propuseram a discuti-lo e uma delas será exposta na subseção que a esta se segue.

\subsection{Crítica às "Sete Teses"}

Mattei (2014), por sua vez, realizou uma análise acerca das "Sete Teses do Mundo Rural Brasileiro" que, embora considere muitos dos fenômenos expostos por Buainain et al (2013), 
refuta a forma como estes são diagnósticos (assim como algumas das medidas propostas). Sua crítica se sustenta na falta de historicidade analítica que, mesmo trazendo colocações referentes à época da "Revolução Verde", não fazem jus à formação do processo colonizador do rural brasileiro ao mitigarem a relevância da concentração de terras, da expropriação dos recursos naturais e da escravidão (MATTEI, 2014, p. 106).

Segundo o autor, a forma como as dimensões "Quem, Como e Quando" são tratadas acaba minimizando efeitos contraditórios sociais e ambientais da modernização do campo, além de mitigar questões sedimentadas como a modernização conservadora e dependente da aristocracia rural $^{4}$ e o efeito do boom das commodities agrícolas, impulsionado pelo crescimento da demanda chinesa na década de 1990, para o desenvolvimento rural. Além disso, o autor (MATTEI, 2014) indica que muitas das políticas publicas voltadas ao ambiente agronegocial e criticadas por Buainain et al (2013) visaram corrigir gaps deixados no primeiro processo de modernização (60's) agropecuária e que a relativização de questões como a concentração da propriedade da terra e do problema das relações de trabalho no campo correspondem a uma confusão entre desenvolvimento puramente agrícola (referente, principalmente à produtividade e geração de lucros) e desenvolvimento agrário (incorporando à dimensão econômica questões sociais, ambientais, institucionais e políticas), embora ambos se inter-relacionem.

Mesmo reconhecendo que a produção passou a depender cada vez mais de investimentos em infra-estrutura, máquinas e tecnologia, Mattei (2014) pondera ao indicar que a terra se mantém como um ativo financeiro de grande valor ao expor taxas semelhantes de arrendamentos em séries históricas. Ademais, indica que a maior acumulação decorrente de produtividade também se apóia em questões mercadológicas e na expansão geográfica em áreas agriculturáveis. O movimento agroindustrial que se deu emulado por grandes latifúndios privados, monocultura, e eficiência produtiva por alta taxa de utilização tecnológica proporciona um entendimento que vincula o ambiente rural brasileiro à mecanização e ao alto desempenho econômico, caracterizando todas e quaisquer formas distintas que sejam presentes no "mundo rural" como atrasadas e empecilhos à evolução (MATTEI, 2014). Ou seja, para o autor, a publicação das "Sete Teses" visa diminuir os problemas referentes à questão agrária, enaltecer o papel da agropecuária realizada por poucos e grandes produtores devido sua

4 Tese exposta por Graziano Silva (1982) em que o processo de modernização do campo ocorreu com predomínio em propriedades oriundas da aristocracia rural. 
eficiência econômica e diminuir o papel do Estado como regulador dos processos produtivos agropecuários.

Contudo, Mattei (2014) ressalta que estes apontamentos são resultado de um fenômeno que não é exclusivo do setor agropecuário e reflete uma inclinação da trajetória econômica do país que propiciou a formação de uma sociedade com características urbano-industriais e que, atualmente, defrontamo-nos com uma nova fase de transição. Sendo assim, mitigam-se alternativas com apelo ambiental e social pode ser reflexo da subestimação do potencial desta mudança. Renting (2012), de certa forma, se aproxima desta constatação ao explanar sobre a subestimação dos impactos positivos de cadeias agroalimentares alternativas se apropriando do conceito de "sociologia das ausências e emergências", tecido por Santos (2003). Tal conceito indica ser uma reação das concepções organizacionais dominantes ignorar modelos alternativos de organização, sendo, inclusive, do seu interesse. Com isso, a análise de Mattei (2015) acerca das teses propostas denota a relevância dada àqueles aspectos e parâmetros com base na produtividade, ou seja, as teses se relacionam mais com o desenvolvimento agrícola do que com o agrário.

O papel do Estado também é um importante ponto de divergência entre os textos. Uma vez qualificadas, pelo segundo autor, as mudanças institucionais da década de 1990 como referentes ao Consenso de Washington, expõem-se seus impactos para a agropecuária brasileira. Tais medidas se baseavam em políticas neoliberais com proposição de desregulamentar as atividades econômicas (agrícolas, neste caso) e possibilitar que agentes econômicos privados pudessem determinar os passos do desenvolvimento setorial. A malha institucional específica desta fase e do setor se desenvolveu, portanto, com medidas como a promulgação de leis de direitos de propriedade de patentes e cultivares e destinação de parte dos tributos para pesquisa (TEIXEIRA, 2013).

Concomitantemente a isto, se mantiveram algumas políticas que, de certa forma, possuem caráter protecionista, principalmente no tocante a reparação de perdas decorrentes de política cambial (Lei Kandir ${ }^{5}$ ), foram institucionalizados fundos de desenvolvimento para as regiões Centro-Oeste, Norte e Nordeste (mesmo que estes não eram restritos a investimentos em agropecuária), foram anistiadas dívidas agrícolas referentes ao Sistema Nacional de Crédito Rural e, por fim, se institucionalizou o Programa Nacional de Fortalecimento a Agricultura Familiar.

5 Lei complementar brasileira $\mathrm{n}^{\circ} 87$ que entrou em vigor em 13 de setembro de 1996 no Brasil, dispondo sobre o imposto dos estados e do Distrito Federal em operações relativas à circulação de mercadorias e serviços ( $\underline{\text { ICMS }}$, isentando do tributo os produtos e serviços destinados à exportação. 
Estes episódios, sustentados por Mattei (2014) como indicação de que o Estado permanece atuando de forma significativa no setor, são somados à constatação de que, mesmo no período posterior a 2003, a União, por meio de renúncia fiscal e aportes via financiamento direto e BNDES, destinou quantias superiores àquelas da década anterior para financiamento da agricultura empresarial, possibilitando a estruturação de uma matriz agroindustrial competitiva. Ambos os textos, portanto, discutem a questão rural brasileira, suas dimensões e características e, evidentemente, o encadeamento dos atores ali envolvidos. Os pontos de maior divergência entre os textos são os papéis da terra e do Estado para o desenvolvimento rural e a questão agrária. De certa forma, uma leitura atenta possibilita encontrar complementaridades em suas apresentações que evidenciam a relação do contexto atual do setor agropecuário com os incentivos e restrições impostos pela evolução institucional do país.

\section{O MUNDO RURAL BRASILEIRO: EVOLUÇÃO E ATUALIDADE POR CATEGORIAS ANALÍTICAS EVOLUCIONÁRIO-INSTITUCIONALISTAS}

Acredita-se que a leitura realizada a partir da obra de pesquisadores que vinculam o tema desenvolvimento ao aparato institucional que orbita as atividades político-econômicas de uma nação seja subsídio suficiente para o entendimento das análises que se darão daqui para frente. O texto "As Sete Teses Sobre o Mundo Rural Brasileiro", de Buainain et al (2013) é um rico compêndio de informações publicadas em relatórios e análises sobre o tema, e visa deixar bastante clara a proposta de que o objeto estudado (o mundo rural brasileiro) se transformou de forma significativa e, com isso, deve ser tratado a partir desta nova fotografia. Mattei (2014), corrobora com os demais autores ao evidenciar tais mudanças que, sinteticamente, são: a alta modernização da agricultura e suas externalidades referentes às diferentes dimensões passíveis de inclusão em análises desenvolvimentistas (econômica, social, ambiental, por exemplo). De certa forma essas características vêm desde um período colonial e denotam que instituições foram sendo modeladas a partir de demandas político-econômicas próprias, podendo, assim, causar deturpações nas demais esferas do desenvolvimento.

Estas externalidades, acredita-se, podem ser bem evidenciadas, por exemplo, como causa e conseqüência simultâneas daquilo exposto por Alves e Rocha (2010) com base nos dados do Censo Agropecuário de 2006 realizado pelo Instituto Brasileiro de Geografia e Estatística (IBGE), em que apurou-se uma significativa concentração de valor bruto de produção, na qual a imensa maioria dos estabelecimentos produtores agrícolas - cerca de 2/3 do total - apropriase de míseros $3 \%$ da renda absoluta do setor. Ademais, menos de $1 \%$ dos estabelecimentos, à época, era responsável por mais de $50 \%$ da renda total. Os posicionamentos conflitantes entre 
as obras se dão, no entanto, à medida que aqui e ali os pesquisadores se posicionam com relação aos motivos pelos quais esta realidade se instalou, além da forma com que esta nova situação deve ser tratada.

\subsection{Estado e Tecnologia: o modelo agrícola bifronte e a questão agrária}

Os valores, a cultura, as regras, as normas, as leis, os códigos de conduta, ou seja, as instituições em suas distintas formas e interpretações, influenciam de forma direta uma determinada sociedade em termos de como constitui suas bases e lida com seus problemas. A tomada de decisão dos agentes envolvidos (sejam eles pertencentes aos diversos estratos sociais), por conseguinte, possui influência direta nos processos de desenvolvimento, repercutindo no sucesso ou fracasso ao atingir seus objetivos. Nota-se, portanto, que ao exemplo da evidenciação de Veblen acerca da predominância das instituições de cunho predatório na sociedade industrial, o desenvolvimento do rural brasileiro passou pelos mesmos critérios. Uma vez que a agricultura sempre foi tida como importante motor para o desenvolvimento econômico, seu enquadramento estratégico é forjado sob tais critérios. Zysman (1994) propõe uma abordagem analítica sustentada no fato de que as trajetórias de crescimento são historicamente enraizadas. Tendo como ponto de partida uma análise da dimensão econômica de uma nação, cada economia consiste em uma estrutura institucional, e esta é a função do desenvolvimento político e industrial de cada país. É importante a análise histórica, uma vez que estas instituições frequentemente são evidentes somente na história, e muitas instituições e arranjos sociais que antecedem as sociedades modernas acabam por modelar os arranjos atuais.

Sendo assim a estrutura institucional que modela a economia, combinada com a sua estrutura industrial no sentido clássico da organização industrial, codifica um sistema de incentivos e contrangimentos (empecilhos) que define os interesses, molda e canaliza as ações dos atores. Este sistema de interesses e interação entre os agentes promove uma lógica política particular a cada mercado, dando um caráter substantivo às diferentes lógicas de mercados. Com isso, determinada lógica de mercado, específica a uma determinada estrutura institucional nacional, conduz os atores às estratégias e ao desenvolvimento dos produtos e processos do sistema nacional em questão. Uma lógica política e de mercado induz a um determinado padrão estratégico (das companhias e de políticas públicas) que possibilitam com que determinadas especificações e capacitações, únicas àquele sistema e país, se desenvolvam. Vale ressaltar que 
este sistema se emula em concordância às demandas institucionais de grupos que, quando não hegemônicos, são, ao menos, politicamente representativos.

Ao analisar o caso da agricultura e da agropecuária como o componente agrícola do "mundo rural", nota-se que o cenário atual não pode ser visto como um fenômeno espontâneo, tendo que ser contextualizado às decisões e instituições que foram conduzindo-o ao seu status presente. Tanto na obra de Buainain et al (2013) quanto na de Mattei (2014) os autores lançam mão do recurso de historicidade para subsidiar suas propostas analíticas. Entretanto, no segundo, se expõe uma crítica ao retorno histórico recente dos fatos, acreditando que a busca de fatos da metade do século XX mitigava aspectos relevantes à formação do cenário agrícola e agrário nacional, referentes à escravidão e à colonização. Embora a análise das "Sete Teses" esteja embasada em três planos - a temporalidade do processo (quando), grupos sociais (quem) e os meios catalizadores e oportunidades (como) que consolidam este novo cenário -, a crítica se sustenta na proposição de que fenômenos anteriores são determinantes em cada um destes supracitados planos.

Conforme sinaliza Mattei (2014), a oferta de crédito rural, a criação de meios de capilarização de tecnologias e instituições públicas como vetores de inovação e pesquisa agrícola (referentes às influências da Revolução Verde) não são suficientes para explicar tal fenômeno, uma vez que as implicações das ferramentas estruturais colonizadoras promovem impactos permanentes nas diferentes esferas da evolução de uma nação, consolidando instituições correlatas. Nota-se a importante deixa que este apontamento abre para uma rigorosa análise institucionalista que incorpore hábitos de vida e de pensamento que, devido uma incorporação às atividades produtivas agrícolas, influencia no panorama presente em análise.

Esta discussão traz à tona o caráter estratégico das ações estatais como direcionador da trajetória desenvolvimentista do setor. Os autores divergem, de certa forma, no processo de promoção de competitividade galgado pela agricultura moderna brasileira, no que se refere as dimensões “Quem, Como e Quando". Evidente, porém, é que a as decisões estratégicas de outrora determinaram uma trajetória tecnológica que permitiu o cenário atual, já caracterizado acima, e no qual a agricultura foi eleita como uum propulsor ao desenvolvimento econômico.

Seguindo o conceito de Estratégia Nacional de Desenvolvimento (BRESSER-PEREIRA, 2006; BIELSCHOWSKY, 2012), promoveu-se uma teia institucional que alavancou o setor agrícola ao ponto que, leis e políticas econômicas, sociais e tecnológicas se deram no sentido de diluir gargalos à economia, compartilhando riscos e incertezas e estimulando seu crescimento. Contextualizando práticas políticas ao caso brasileiro, a utilização de seu vasto 
território como fonte de recursos naturais tornou-se fator preponderante às decisões e, sendo assim, direcionou a trajetória de desenvolvimento agrícola para que galgasse os mais altos padrões de competitividade em mercados globais. Outro fator exposto que indica a ativação de uma forte demanda efetiva é o potencial mercado interno. Mas, a modulação do setor se deu, principalmente com o final da décadda de 1980 e o início da de 1990 de forma a voltar-se para a exportação de commodities, finalmente, configurando sua principal característica na atualidade. Aqui, o meio-ambiente expressa como um incentivo vigente na modulação dos hábitos de vida e pensamento. Assim sendo, questiona-se: teríamos iniciado este processo intenso de desenvolvimento da produção agrícola nacional, nestes moldes, caso não tivéssemos essa grande disponibilidade de recursos naturais?

Importante ponto desta etapa da discussão são os motivos pelos quais instauraran-se tais características nesta década. De acordo com Buanain (2013), a primeira onda modernizadora da agricultura (brevemente exposta acima, referente à Revolução Verde), permitiu que o setor estivesse preparado institucionalmente para as mudanças referentes a um novo padrão de financiamento agrícola, cuja participação estatal era reduzida, e por uma política cambial mais favorável às exportações. Observando que, além disso, houve um crescimento significativo das demandas globais por cereais (mais precisamente do complexo milho e soja), Mattei (2014) aponta que tais mudanças institucionais tiveram relevância questionável no que se refere ao desenvolvimento rural, uma vez que instaurava-se de vez um sistema que hoje resulta nas questões segregacionistas registradas nos primeiros parágrafos desta discussão. Sobre a modernização no período relativo à Revolução Verde, novamente, a inserção de novas tecnologias forçou uma mudança institucional significativa no campo, conduzindo os produtores a novos hábitos de vida, em prol da eficiência produtiva. E os incentivos para tal investimento tecnológico ocorreu por própositos diversos.

Este período, cujo relacionamento político-econômico entre financiadores e financiados se sustentou em proposições neoliberais como as do Consenso de Washigton, solidificou um "pacote tecnológico" para a agricultura nacional altamente produtivo e eficiente economicamente. Tal consolidação, que não é particular ao caso brasileiro, denota a opção por um determinado Sistema de Inovação característico pela proteção dedetrminados agentes das cadeias produtivas. De certa forma, a atuação do estado, embora tenha propiciado incentivos diretos a regiões menos desenvolvidas e à Agrigultura Familiar, não possibilitou que milhares de pequenos estabelecimentos agrícolas gozassem dos benefícios apontados, deixando-os à margem dos avanços. Sendo assim, esta dinâmica institucional descrita embora tenha 
alcançado objetivos desenvolvimentistas em determinadas esferas, não permitiu ganhos absolutos.

Notam-se manifestações, ao longo dos anos, de uma escolha por determinada trajetória. O questionável, aqui, é o fato de apenas um grupo pequeno e melhor preparado de produtores lograr de tais benefícios. É o então chamado modelo bifronte da agricultura nacional, em que o grupo capaz de assimilar a tecnologia vigente responde por quase toda a produção, promovendo concentração de renda e terra e, tornando hegemônico o pacote referente à dita agricultura moderna, enquanto os demais tornan-se dependentes de políticas públicas para sobreviver (BUAINAIN et al, 2013). Reintroduzir este imenso grupo de indivíduos no círculo hegemônico “tecno-econômico" não é simples, dado seu afastamento das rotinas inovativas e a importância do aspecto temporal para assimilação dos processos. Ao permitir o afastamento deste grupo optou-se, num longínquo passado, pela sua submição a um determinado caminho de desenvolvimento cuja volta alternativa é dificultada. É o que Niosi (2002), por exemplo, chama de path dependence, ou dependência de uma determinada trajetória.

Seria isso, portanto, um processo de incompatibilidade entre tecnologias físicas utilização de sistemas produção integrada, fertilizantes e demensivos específicos, culturas e espécies geneticamente melhoradas - e tecnologias sociais - capacidade de absorção e assimilação prática destas tecnologias (NELSON e NELSON, 2002). A utilização adequada e efeciente dos recursos tecnológicos dependeriam da institucionalização destas tarefas pelo grupo social em questão, reforçando a indicação de Buainain et al (2013) em relação à incapacidade do estrato de produtores diagnosticado como ineficiente economicamente em assimilar o novo padrão competitivo da agricultura moderna.

A constatação de sua não participação da parcela entendida como altamente rentável do meio rural reflete a falta de interação destes atores com os demais componentes do sistema visto como hegemônico. Tal exclusão impede o gozo dos benefícios provindos da competição, das transações comuns, das redes de relacionamento e da transferência de conhecimento a longo prazo, visto que o caráter cumulativo do conhecimento é preponderante para a eficiência do sistema como um todo (EDQUIST, 2005). Diante de barreiras impostas pelos padrões técnico e econômico, explicíta-se a falha na institucionalização das tecnologias sociais - prérequisito para sua ideal condução (PEREIRA e DATHEIN, 2012) entre o coletivo de produtores incapacitados de participar dos processos de transferência de conhecimento e incorporação das tecnologias físicas. É nítida uma relação deste estrato de produtores alheia às demandas técnicas exigidas, uma vez que hábitos anteriores influenciam diretamente o 
comportamente presente (HODGSON, 2002). De mesma forma, a habituação necessária que permitiria-os a partilhar dos resultados de pacotes altamente tecnológicos demandaria investimentos profundos em seu desenvolvimento intelectual.

Para Mattei (2014), tal fenômeno é inquestionável. Seu contraponto está nas formas de lidar com ele, principalmente no que se refere às políticas voltadas à reforma agrária e a desqualificação de alternativas mais próximas à realidade deste atores subjugados. Sobre a questão agrária, enquanto os autores ligados à Embrapa consideram que as políticas agrárias sejam obsoletas e desnecessárias, devendo ser substituídas por políticas que viabilizem que este grande grupo de produtores marginalizados sejam capazes de se inserir nos mercados competitivos, ele considera que a questão agrária ainda seja indispensável para remediar a situação, uma vez que a supremacia do padrão agrícola altamente tecnológico vincula-se intimamente com a ampliação da problemática agrícola. Não há dúvidas de que a propriedade da terra é fundamental e que a sua não disponibilidade influencia sobremaneira na manutenção destes produtores alheios às tecnologias postas como ideias. $\mathrm{O}$ ponto aqui estaria na identificação do tipo de utilização que estes produtores operariam nestas terras, se estariam preparados para as demandas suas e da sociedade, e, em caso de alternativas ao mainstream agrícola, como demonstrá-las promissoras ao coletivo (em distintos aspectos), de modo a institucionalizá-las não somente para produtores como para a sociedade em geral.

Buainain et al (2013) indicam que tal discussão deva ser superada uma vez que o pacote tecnológico entendido como única forma competitiva de agricultura reduziu a relevância da terra na composição do valor total da produção. Com isso, tais autores indicam que, se o objetivo é incorporar os pequenos produtores ao mainstream produtivo, as políticas públicas deveriam se dar no sentido de permitir que estes sejam capacitados e que o ambiente institucional incentive sua incorporação. Contudo, a partir de uma visão de desenvolvimento rural menos economicista, além da terra persistir como ativo de altíssimo valor dentro dos cenários agrícola e agrário, colocar o modelo agroindustrial como único é mitigar tanto seus malefícios sociais e ambientais quanto os benefícios de propostas alternativas de produção agrícola (MATTEI, 2014).

Torna-se, neste ponto, importante trazer à discussão o conceito de "paradígma tecnológico", proposto por Dosi (1988), em que decisões institucionalizadas outrora emulam uma trajetória tecnológica a ser percorrida em decorrência de padrões ou modelos de princípios que derivam do conhecimento existente, definindo o campo de investigação, os problemas a serem resolvidos e os procedimentos para resolvê-los. E, portanto, fica evidente o 
posicionamento de Buainain et al (2013) em relação à necessidade de alta produtividade diante do padrão competitivo do mercado agronegocial mundial no qual o Brasil é um líder. De qualquer forma, justifica-se a crítica de Mattei (2014) quando lida com base nos escritos de Veblen no longínquo final do século XIX. Ali apontou-se que as instituições são forjadas sem levar em consideração todas as camadas sociais, deixando demandas em aberto (quando não produzindo novas). O conhecimento e a tecnologia se propaga sob consenso de interesses (VEBLEN, 1865), e, assim sendo, geram conflitos àqueles cujos interesses são outros.

Da mesma forma, a ponderação de Mattei (2014) se dá no sentido de que a incorporação de tecnologias sociais e físicas não condizentes com o contexto dos indivíduos pertencentes ao ambiente de operação de um sistema eleito torna-o falho. Talvez poderiam existir objetivos específicos paralelos aos do grande sistema agrícola nacional que ramificassem as atividades econômicas do campo de acordo com aspectos enraizados nas distintas comunidades. E, de certa maneira, iniciativas neste sentido podem ser vistas (embora ainda relativizadas diante do mote central do agronegócio brasileiro). Esta seria uma hipótese que se aproxima dos Sistemas Regionais de Inovação, cujas interações entre os agentes valorizam o enraizamento de instituições comuns à localidade em questão, e, com isso, o aprendizado interativo corresponde aos padrões tecnológicos almejados e à bagagem cultural existente (KRETZER, 2009).

Neste sentido, a fuga da "commoditização agrícola" poderia ser encarada como uma alternativa de desenvolvimento distinta àquela posta como única e, talvez, se aproximaria mais de instituições, hábitos e institntos que permanecem no meio rural. Esta alternativa, se conduzida por rigores técnicos compatíveis tanto à realidade do campo quanto às demandas do mercado, recupera este encadeamento produtivo relegado pelos padrões competitivos agrícolas globais altamente competitivos. Pode-se, inclusive, avaliar a viabilidade em, com o aumento da ativação de mercados locais, contemplar uma frente de expansão indicada por Bielschowsky (2012) e que é de extrema relevância para uma Estratégia Nacional de Desenvolvimento em um país das dimensões do Brasil, o consumo interno.

Poder-se-ia, a partir de tal perspectiva, viabilizar uma trajetória tecnológica ampliada aos moldes da que sugere Silveira (2013), convergendo interesses voltados à produção agrícola exportadora e às produções locais. Assim, como propõe Navarro (2013), discussões acerca da redistribuição de terra e dos malefícios do agronegócio se diluiriam. Valorizar-se-iam, a partir de uma visão bastante estratégica de abastecimento, produtores já estabelecidos no campo que atualmente estejam padecendo de uma cruel segregação do sistema hegemônico, uma vez que não estão incorporados ao mainstream técno-produtivo. 


\section{CONSIDERAÇÕES FINAIS}

O debate sobre o desenvolvimento rural brasileiro possui uma importante constação desde os últimos dados censitários disponíveis: um enorme grupo de produtores está alheio às condições necessárias para ativação dos padrões exigidos pela agricultura moderna. Enquanto este estrato social, mesmo sobre a influência de políticas públicas de diferentes naturezas, é marginalizado, um diminuto grupo de atores altamente capacitado conduz o agrenegócio brasileiro e representa ferramenta indispensável à balança comercial do país. A construção deste painel se deu, aqui, embasada nas opiniões, ora divergentes, ora convergentes, de Buainain et al (2013) e Mattei (2014).

Analisar tais dados por lentes institucionalistas permite-nos um entendimento significativo sobre a dinâmica com a qual tal situação se instaurou. Mesmo os autores de ambos os textos buscando marcos legais e científicos e aspectos referentes à natureza da vida no meio rural, a falta de um endosso teórico-analítico impossibilita um avanço significativo na discussão. Trazer ao debate o modelo de desenvolvimento institucional vebleniana, contemplando instintos e indivíduos, hábitos de pensar e de vida, estratos sociais e grupos dominantes, instituições e interesses, torna claros os objetivos e qualifica as demandas.

Aspectos referentes à forma com a qual questões agrícolas e agrárias foram tratadas ao decorrer da evolução do Estado brasileiro até a instalação do cenário atual permitem um importante link com o aparato analítico escolhido, indicando que avanços na análise deste fenômeno sob tais perspectivas permitirá resultados fortuitos. Buainain et al (2013), embora indiquem pelas referências da obra que sua análise se sustenta em uma perspectiva de constante mudança tecnológica, não incorporam dimensões institucionais que fogem da alçada mercadóligica (dando ênfase para estas últimas). E Mattei (2014), mesmo reivindicando a incorporação de fatores negligenciados e apresentando uma importante robustez de dados como contra-argumento, não entra a fundo na matriz institucional das sociedades do campo (principalmente no que se refere aos costumes, valores, tabus, etc...). Estes atributos sustentariam de forma mais sólida suas argumentações.

Políticas de cunho assistencialista e de reforma agrária, assim como a eleição dos padrões tecnológicos da agricultura moderna e industrial como indispensáveis para o desenvolvimento rural mostraram-se como as principais fontes de conflito entre ambos pontos de vista. Ademais, caracterizar o papel do Estado para com a situação diagnosticada se fez indispensável para a leitura deste panorama. Ficou evidente que, entre as duas obras existe discrepâncias entre a 
forma de atuação tanto em relação ao passado quanto em relação às propostas futura. De qualquer forma, as referências institucionalistas sugerem que, analisado a partir de teorias hodiernas, o papel do Estado deva ser a condução e manutenção de um ambiente institucional que permita o desenvolvimento harmônico das atividades ali empregadas.

Quando as colocações contidas nos dois artigos foram analisadas sob a perspectiva de uma Estratégia Nacional de Desenvolvimento, que segundo Bresser-Pereira (2006) demanda um pacto nacional, institucionalizado em conformidade a objetivos comuns da nação, a evidenciação dos conflitos entre agentes demonstra a necessidade do Estado em equacionar as contrapartidas dos distintos interesses, mediando as ações político-econômicos. De qualquer forma, nota-se que as críticas de ambas posições denotam um hiato entre os objetivos e análises do contexto agrário e agrícola do país.

\section{REFERÊNCIAS}

ALVES, E.; ROCHA, D. P. Ganhar tempo é possível? In: GASQUES J. G.; VIEIRA FILHO, J. E. R.; NAVARRO, Z. (Org.). A agricultura brasileira: desempenho, desafios, perspectivas. Brasília, DF: IPEA, 2010. p. 275-290.

BARDIN, L. Análise de Conteúdo (L. de A. Rego \& A. Pinheiro, Trads.). Edições 70. Lisboa. 2006.

BIELSCHOWSKI, R. Estratégia de desenvolvimento e as três frentes de expansão no Brasil: um desenho conceitual. Economia e Sociedade. Campinas. V. 21, número especial, p. 729-747, dez 2012.

BRESSER-PEREIRA, L. C. Estratégia Nacional e Desenvolvimento. Revista de Economia Política, vol. 26, n 2 (102), pp. 203-230, 2006.

BUAINAIN, A. M; ALVES, E.; SILVEIRA, J. M. da; NAVARRO, Z. Sete teses sobre o mundo rural brasileiro, Revista de Política Agrícola, Brasília, DF, ano 22, n. 2, p. 105-121, abr./jun. 2013.

CAVALIERI, M.A.R. O surgimento do institucionalismo norte-americano de Thorstein Veblen: economia política, tempo e lugar. Economia e Sociedade, v. 22, n.1, pgs. 43-76, 2015.

CONCEIÇÃO, O. A. C. Instituições, crescimento e mudança na ótica institucionalista. Tese. Porto Alegre: Fundação de Economia e Estatística Siegfried Emanuel Heuser, 2001.

CONCEIÇÃO, O. A. C. A dimensão institucional do processo de crescimento econômico: inovações e mudanças institucionais, rotinas e tecnologia social. Economia e Sociedade, Campinas, v. 17, n. 1 (32), p. 85-105, abr. 2008

CONCEIÇÃO, O. A. C. Há compatibilidade entre a "tecnologia social" de Nelson e a "causalidade vebleniana" de Hodgson?Revista de Economia Política, vol. 32, n. 1 (126) p. 109127, jan-mar/2012 
EDQUIST, C. Systems of Innovation: Perspectives and Challenges. In Fagerberg, J., Mowery, D., and Nelson, R. (Eds.), Oxford Handbook of Innovation (pp. 181-208). Oxford, UK: Oxford University Press, 2005.

HODGSON, G. M. Economics and Evolution: Bringing Life Back Into Economics, Polity Press and University of Michigan Press, Cambridge UK, 1993.

HODGSON, G. M. The evolution of Institutions: An agenda for future Teorethical research. Constitutional Political Economy, 13, 111-127, 2002.

HODGSON, G. M. The revival of Veblenian institutional economics, Journal of Economic Issues 41.2: 325-340, 2007.

IBGE. Censo agropecuário brasileiro, 2006. Rio de Janeiro, 2006. Disponível em: <http://www.ibge.gov.br/home/estatistica/economia/agropecuaria/censoagro/2006/>. Acesso em: 14 abr. 2006.

KRETZER, J.Sistemas de inovação: as contribuições das abordagens nacionais e regionais ou locais. Ensaios FEE, Porto Alegre, v. 30, n. 2, p. 863-892, dez. 2009.

MONASTERIO, L. M. Guia para Veblen: um estudo acerca da economia evolucionária. Pelotas: EDUFPEL, 128p, 1998.

NAVARRO, Z. Por que não houve (e nunca haverá) reforma agrária no Brasil? In: A. M. Buainain, E. Alves, J. M. F. J. Silveira, \& Z. Navarro (Orgs.). O mundo rural no Brasil do século 21: a formação de um novo padrão agrário e agrícola :Embrapa, p. 695-724. Brasília, 2013.

NELSON, R. R.; NELSON, K. Technology, institutions, and innovation systems.Research Policy. 31, 265-272, 2002.

NELSON, R. What enables rapid economic progress: What are the needed institutions? Research Policy, 37, pp. 1-11, 2008.

NIOSI, J. National System of innovations are "x-efficent" (and x-effective). Why some are slow learners. Research Policy, 2002.

NORTH, D.C. Institutions, Institutional Change, and Economic Performance. Cambridge University Press, Cambridge, 1990.

NORTH, D.C. Institutions. The Journal of Economic Perspectives, Vol. 5, No. 1, p. 97-112, 1991.

NORTH, D.C. Economic performance through time AER . The American economic review 84 (3), 359-368, 1994.

MATTEI, L. Considerações Acerca de Teses Recentes sobre o Mundo Rural Brasileiro. In: Revista de economia e sociologia rural. Piracicaba, V. 52, Supl. 1, p. 105-124. 2014.

PEREIRA, A. J.; DATHEIN, R. Processo de aprendizado, acumulação de conhecimento e sistemas de inovação: a "co-evolução das tecnologias físicas e sociais" como fonte de desenvolvimento econômico. Revista Brasileira de Inovação, v. 11, n. 1 jan/jun, p. 137-166, 2012.

RAYMER, E. A Man of His Time: Thorstein Veblen and the University of Chicago Darwinists. Journal of the History of Biology , 46:669-698, 2013. 
SILVEIRA, J.M. Agricultura brasileira : O papel da inovação tecnológica. In: A. M. Buainain, E. Alves, J. M. F. J. Silveira, \& Z. Navarro (Orgs.). O mundo rural no Brasil do século 21: a formação de um novo padrão agrário e agrícola :Embrapa, p. 373-394. Brasília, 2013.

TEIXEIRA, G. A sustentação política e econômica do agronegócio no Brasil. Reforma Agrária, edição especial, jul. 2013.

VEBLEN, T. B. Why is economics not na evolutionary science. Cambridge Journal of Economics, v. 22, p. 403-414, 1998. (1 ${ }^{\text {a }}$. Ed. 1898)

VEBLEN, T. B. A teoria da classe ociosa: um estudo econômico das instituições. São Paulo: Pioneira, 1965. (1a. ed. 1899)

VEBLEN, T. B. The instict of workmanship and the state of industrial arts. New York: Viking Press, reimp. 1937. (1a. ed. 1914)

WILLIAMSON, O.E. The economic institutions of capitalism: firms, markets, relational contracting. New York: The Free Press, 1985.

ZYSMAN, J. How Institutions Create Historically Rooted Trajectories of Growth. Industrial and Corporate Change, v.3, n.1, Oxford University Press, Oxford, 1994. 